Environment Conservation Journal 14(3): 123-130, 2013

ISSN 0972-3099 (Print) 2278-5124 (Online)

Abstracted and Indexed

\title{
Ion chromatographic analysis of combined industrial effluent and its impact on seed germination of leguminous seeds
}

\author{
Nishu, Raj Kumar Rampal $\bowtie$ and Sajad Iqbal Khan
}

Received: 09.09.2013

Accepted: 17.11.2013

\begin{abstract}
The present study has been made to assess the impact of combined industrial effluent from Industrial estate Bari Brahamana Jammu on seed germination of leguminous plants. The study revealed that values of anions fluoride, chloride, bromide, phosphate and sulphate and cations sodium, potassium and calcium o decreased with increase in dilution. In general in most of studied seeds it was observed that the values of seed germination percentage and rate of seed germination index decreased with increasing effluent concentration.
\end{abstract}

Keywords: combined industrial effluent, anions, cations, seed germination percentage, index

\section{Introduction}

Industrialization is the central dynamic force for most countries. It is a key growth objective for economy, with heavy investment being made in this sector. It is a pre condition for agricultural development and it induces development in other sectors as well. Industrial growth, economic development and consumerisation indicate a country's progress and life standard of individuals. Increasing pace of industrialization in public and private sectors has also brought new problems along with it. The varying degrees of pollution of water, soil and air are all result of stupendous industrial activities with less attention to its negative impacts on man and environment. Nature's built- in mechanisms and self- regulation ability has been thrown out of gear by the quantity and complexity of wastes generated by the modern society.A wide variety of both inorganic and organic pollutants are present in effluents form tanneries, dyeing textiles, paper and pulp mills, steel industries, distilleries, rubber factories etc. The pollutants include oils, greases, plastics, plasticizers, metallic wastes, suspended solids, phenols, toxins and other chemical substances, many of which are not readily susceptible to

Author's Address

Department of Environmental Science, University of Jammu, Jammu

Email: rajkrampal@gmail.com to degradation and cause very serious pollution problems.The disposal of untreated industrial effluents into environment has caused a lot of damage to soil and vegetation. The industrial wastes are those which are generated and disposed off at the end of manufacturing of the three sources i.e. process wastewater, cooling waste water, sanitary wastewater.The process waste waste is the main contributor to the industrial effluent, which is not only in large quantity but also highly polluted. Industries, which use large amount of water in their processes, include chemical manufactures, steel plants, metal processors, textile manufactures, distilleries, pulp and paper units etc. Due to lack of treatment and improper mode of disposals, the water bodies are polluted and they carry deadly substances. The development of simple low cost treatment methods, coupled with the re-use of effluents in agriculture, offers the most suitable solution in a country like India.The utilisation of industrial effluent for irrigation of crop plants is one of the highly beneficial propositions. In addition to providing large quantities of water, some effluents contain considerable amounts of nutrients, which may prove beneficial for plants. Some work has been done on the performance of various crops irrigated with the effluent discharged from various sources (Padhan et.al, 1999; Ameta et.al, 2003). 
Use of wastewater in agriculture is gaining importance now a days, because of its value as a potential irrigant and a nutrient donor. Use of waste for irrigation makes it possible to conserve the limited water resources for crop production and also prevent pollution of water bodies, as soil is a very good sink. Also, application of some effluents to agricultural land may promote the growth of crops and conserve water and nutrients. A large number of wastes viz. dairy wastes, food processing waste, tannery waste, pulp and paper mill waste etc. have been successfully used for irrigation of crops. Thus, the objective of the utilization of industrial effluents for irrigating crop plants is two-fold. The first and the foremost of this is the safer disposal of the effluents, which may otherwise have adverse effects on the environment and human health. The other objective is to recycle it as irrigation water for its possible fertilizer value.The effluents also alter the physico-chemical characteristics, and flora and fauna of receiving aquatic bodies. In this regard, efforts have been made to determine the effect of industrial effluents on seed germination of various crops such as maize, rice, wheat ,pine , Green gram and catechu .Seed germination is a critical stage that ensures reproduction and controls the dynamics of plant populations, so it is a critical test of probable crop productivity.In the present study attempt has been made to assess the impact of combined industrial effluent from Industrial estate Bari Brahamana Jammu on seed germination of leguminous plants.

\section{Material and Methods}

\section{Ionic analysis of combined industrial effluent}

The combined industrial effluent was collected from the big drain in Industrial estate Bari Brahmana, Samba. .The determination of anionic (fluoride, chloride, bromide, phosphate and sulphate) and cationic (sodium, potassium and calcium) concentration in combined industrial effluent were carried out using 850 professional IC system supplied from Metrohm, Switzerland. The system was connected to a PC-controller; Rapid start - click and analog output for connection to external data systems with or without chemical suppression. For automation tasks, the system was fully automatic, the 250/4.0 I C column for separation of mixture solution and the 863 Compact
IC Auto sampler was used for injecting $20 \mu \mathrm{m}$ sample into IC for analysis. The Metrohm 850 Compact IC system was characterized by Built-in 6-way injection valve, Low-pulsation double piston pump with flow range of 0.2 to $10 \mathrm{ml} / \mathrm{min}$ and maximum pressure of $35 \mathrm{MPa}$ (350 bar,),Pulsation dampener, Insulated column compartment, Detector temperature stabilized to better than $0.01^{\circ} \mathrm{C}$ with temperature range of $25-45^{\circ} \mathrm{C}$ in $5^{\circ} \mathrm{C}$ steps, Data source conductivity detector, Integration automatic, Eluent composition $3.2 \mathrm{mM} \quad \mathrm{Na} 2 \mathrm{CO}_{3}+1 \mathrm{mM}$ $\mathrm{NaHCO}_{3}$, flow rate was constant $0.700 \mathrm{ml} / \mathrm{min}$.

\section{Impact of combined industrial effluent on seed germination}

Tested seeds of Phaseolus aureus Black eyed white beans (Rongi), Phaseolus vulgaris .L (Rajmash) , Viccia faba major (Broad Beans), Vigna mungo (Mung), Vigna radiata Mash, Macrotyloma uniflorum Kulth, Cicer arietum Black gram (Kaala Channa), Viccia faba minor (Small bean) and Pisum sativum (Pea) were procured from the Directorate of Agriculture, Talab Tillo, Jammu (J\&K). Five experimental sets (One Control Set with no treatment of combined industrial effluent was given and four Experimental sets. I, II, III , and IV with $25 \%, 50 \%, 75 \%$, and $100 \%$ combined industrial effluent treatment respectively) each comprising of four petriplates (of 6 inch diameter) with 25 seeds per plate were prepared for each specific seed. Each of the sterilized petri dish was lined with blotting paper and irrigated with $5 \mathrm{~mL}$ of the specific concentrations of combined industry effluent at regular interval.

\section{Parameters Studied}

(a) Percentage Germination:- The number of seeds that germinated were counted at regular ( 1 day) interval and finally after 7 days and thus the percentage of seed germination was calculated at $7^{\text {th }}$ day of sowing for each experimental set.

\section{(b) Germination index (G.I.) $=\mathbf{d} / \mathbf{n}$}

where, n=number of seedlings emerging on day'd'

$d=$ day after planting 
The analysis of cataionic data of combined industrial revealed that sodium, potassium and calcium in the $100 \%$ combined industrial effluent exhibited values of $0.212 \mathrm{ppm}, 0.024 \mathrm{ppm} 0.176 \mathrm{ppm}$ respectively Fig.1. and these values decreased with increase in dilution Figs. 2-4 whereas the analysis of anionic data of combined industrial revealed that anions fluoride, chloride, phosphate and sulphate in the $100 \%$ combined industrial effluent exhibited values of $11.545 \mathrm{ppm}, 1075.463 \mathrm{ppm}$, $57.587 \mathrm{ppm}$ and $126.875 \mathrm{ppm}$ respectively Fig.5 and these also values decreased with increase in dilution, Figs.6-8.

The analysis of data of impact studies on seed germination of Phaseolus aureus revealed that control set and $25 \%$ experimental set exhibited
$100 \%$ value on $3^{\text {rd }}$ day after seed sowing. On $7^{\text {th }}$ day the seed germination index of control set and $25 \%$ experimental set exhibited value of 33.3. The seed germination index decreased with increase of combined industrial effluent i.e. $50 \%, 75 \%$ and $100 \%$ experimental sets exhibited values of seed germination index as 32.5, 28.5 and 27.8 respectively.The analysis of data of impact studies on seed germination of Phaseolus vulgaris revealed that control set exhibited $100 \%$ value on $7^{\text {th }}$ day with seed germination index of 21.8 after seed sowing. Whereas percentage seed germination and seed germination index in $25 \%, 50 \%, 75 \%$ and $100 \%$ experimental sets exhibited decreased value with increasing concentration of combined industrial effluent.

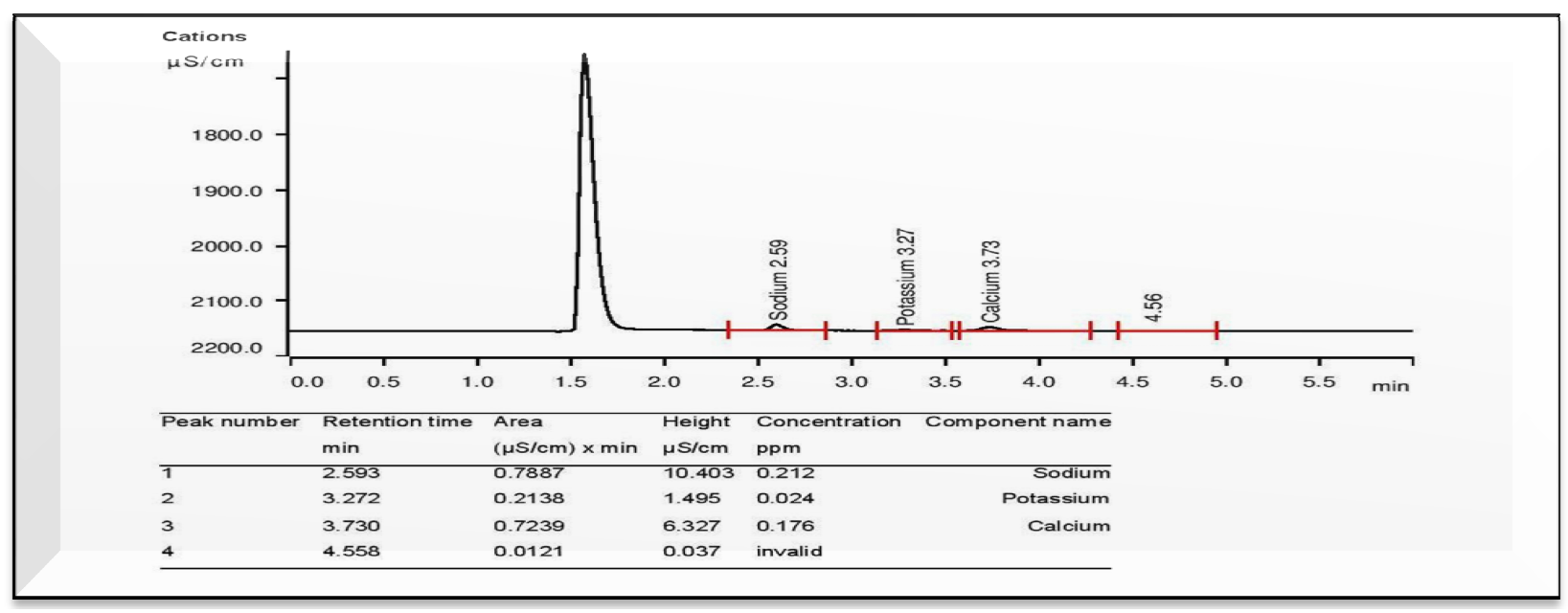

Fig 1: Chromatogram of common cations in $100 \%$ combined industrial effluent

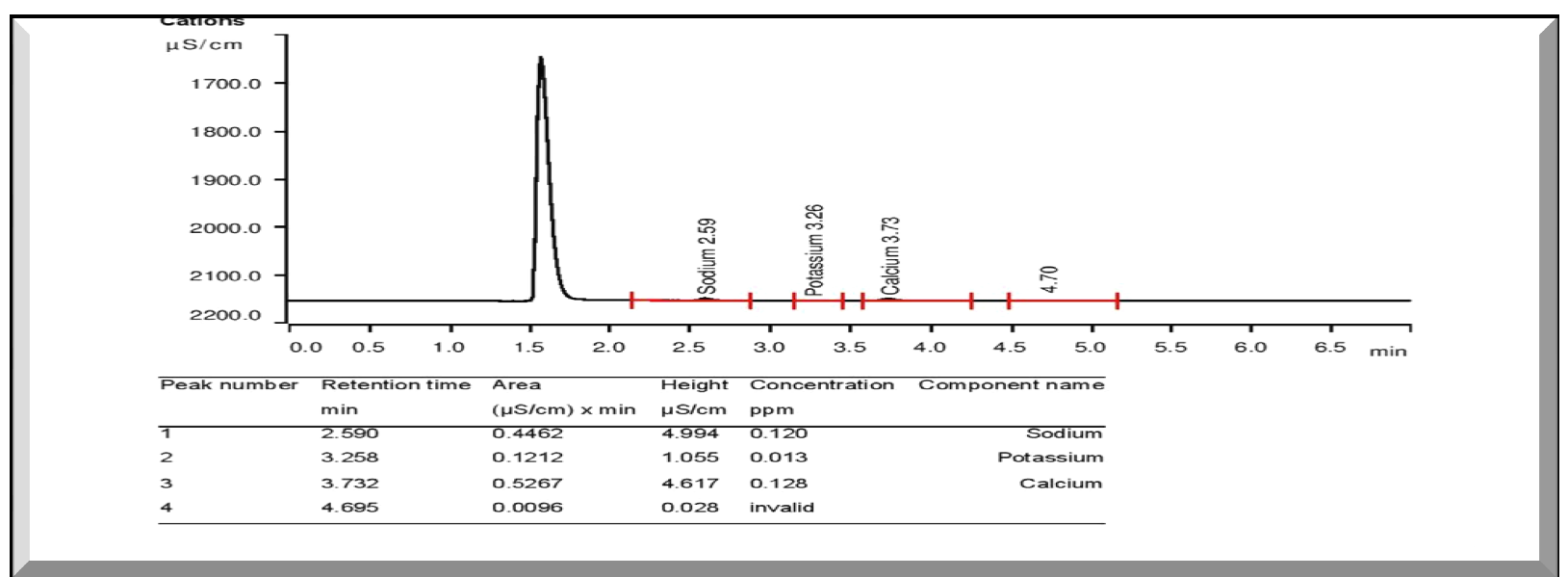

Fig.2. Chromatogram of common Cations in $75 \%$ Combined Industrial effluent 


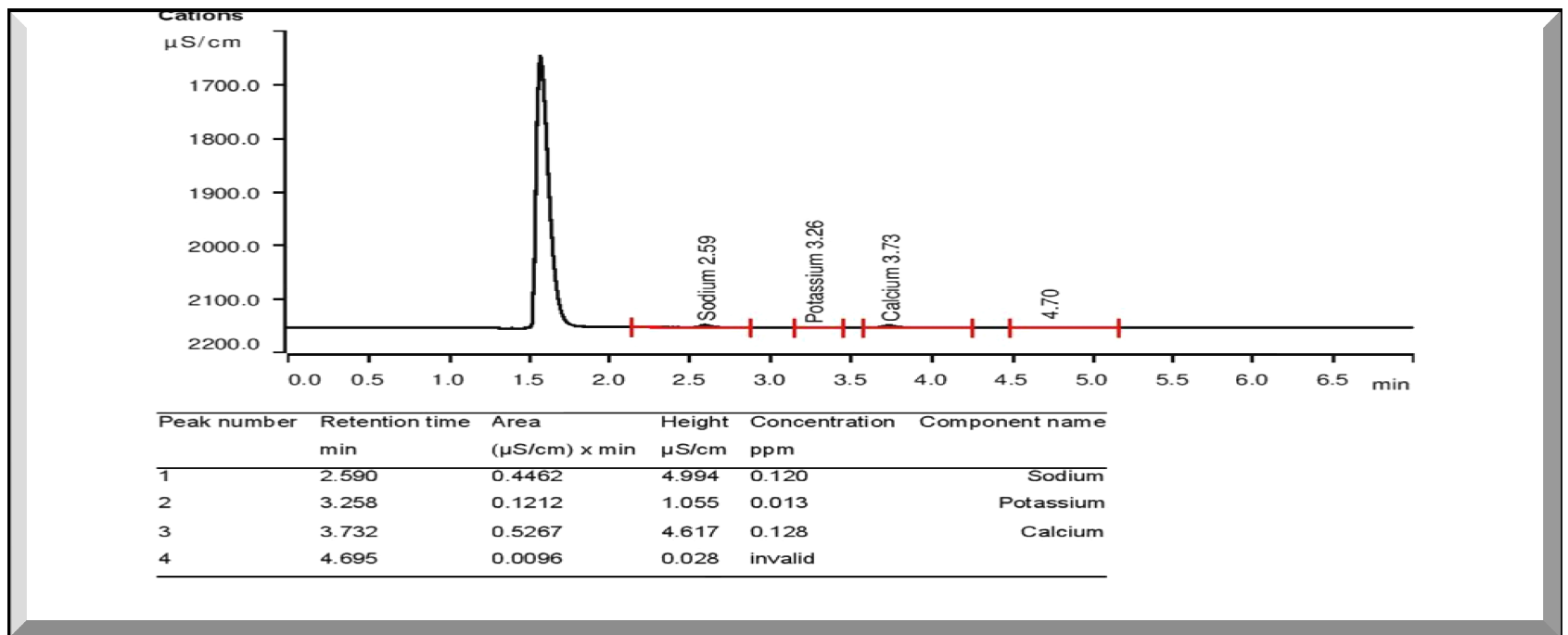

Fig. 3: Chromatogram of common Cations in 50\% combined industrial effluent

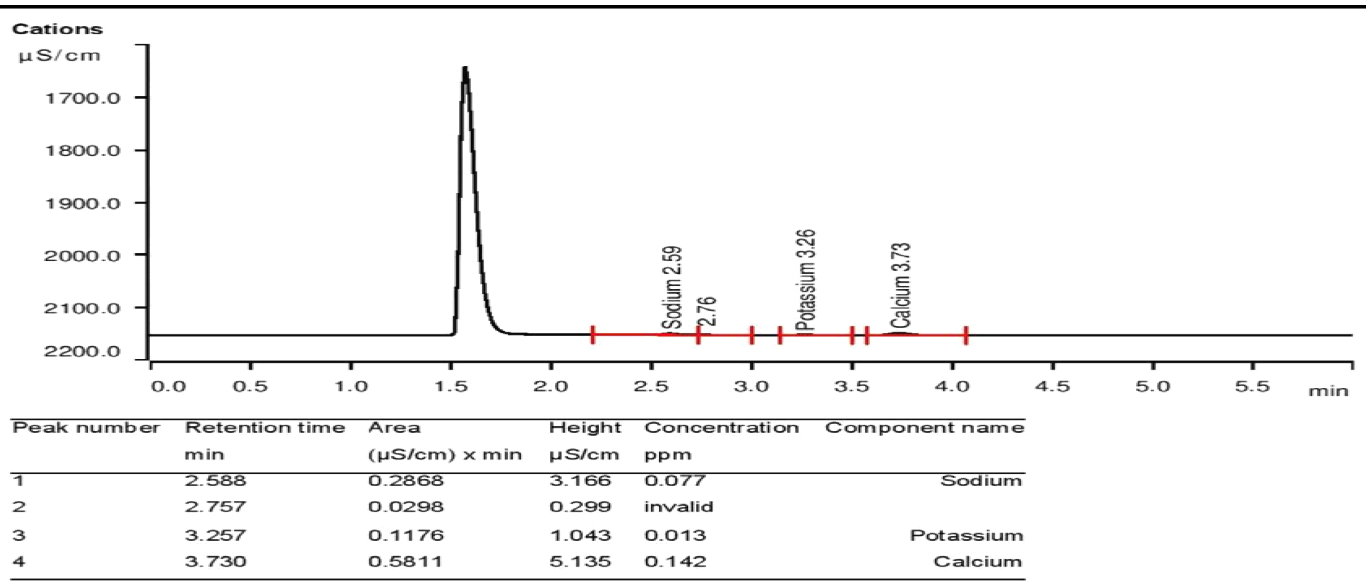

\section{Fig. 4: Chromatogram of common cations in $25 \%$ combined Industrial effluent}

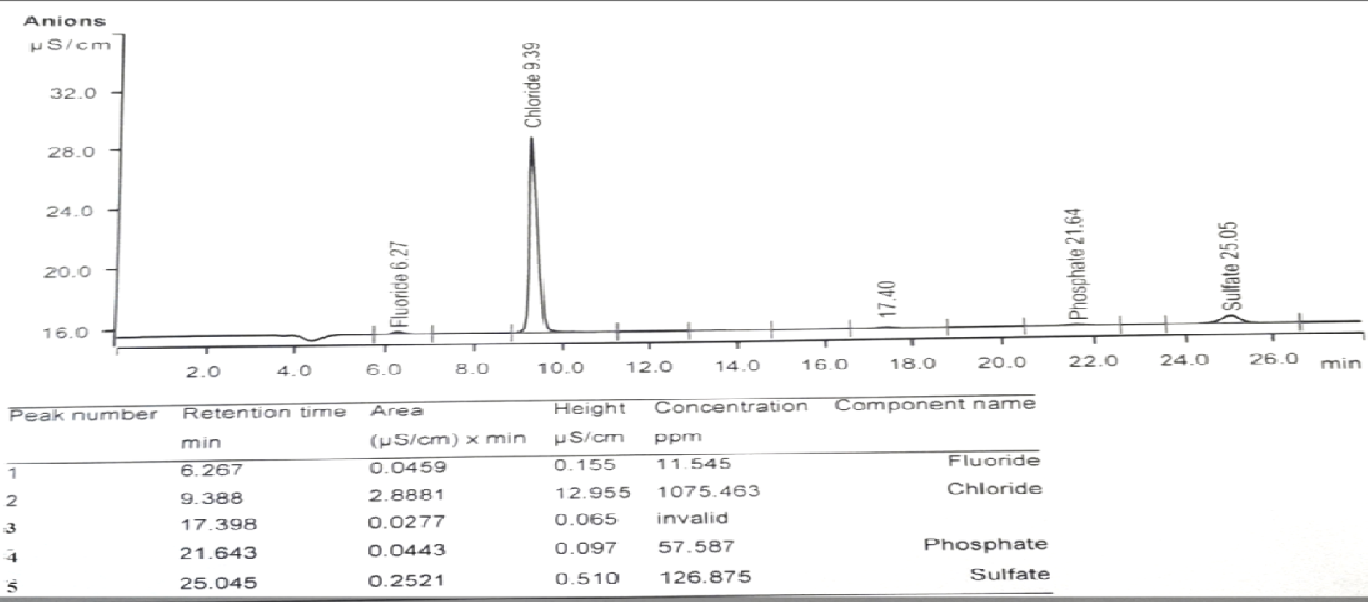

Fig. 5: Chromatogram of common anions in $100 \%$ combined industrial effluent 


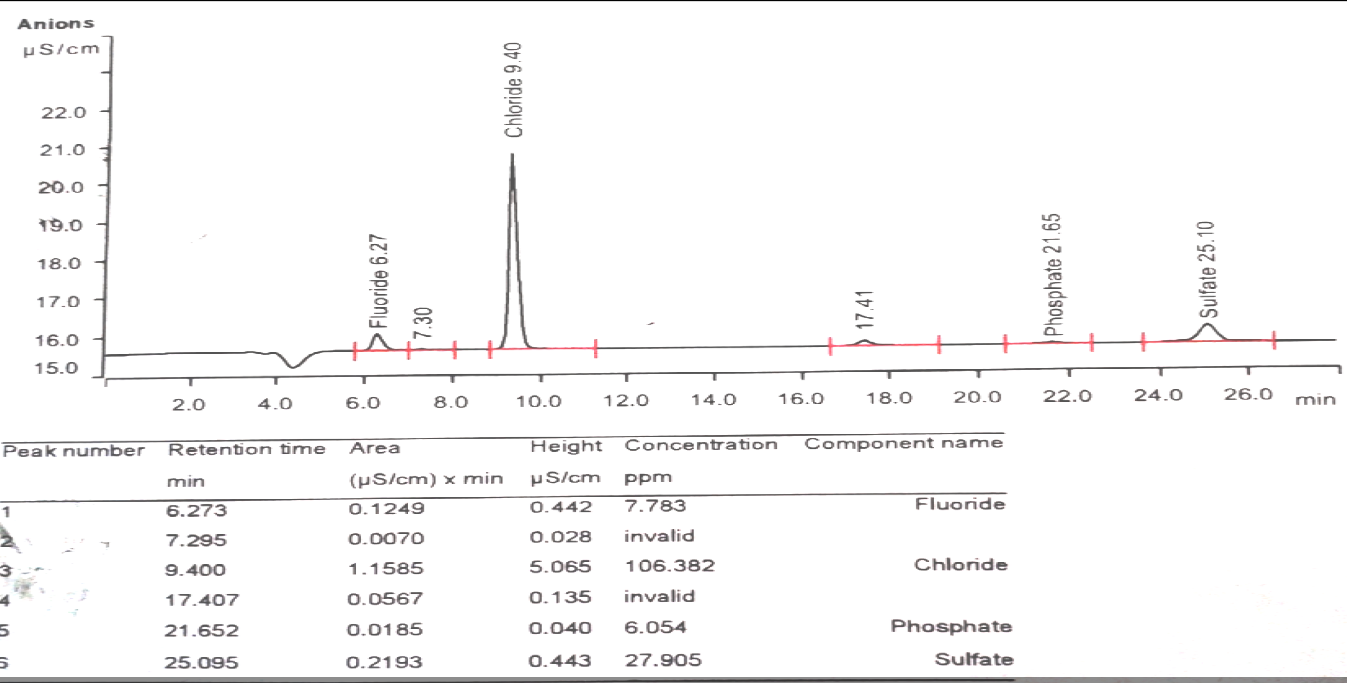

Fig.:6. Chromatogram of common anions in $75 \%$ combined industrial effluent

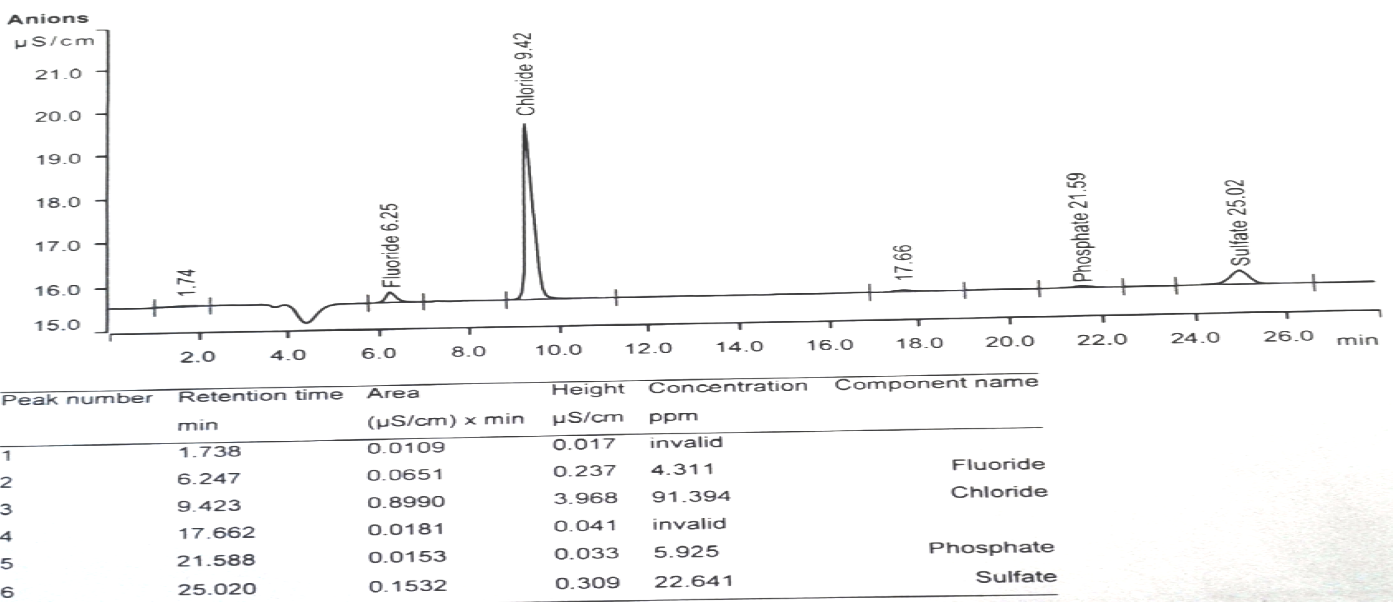

Fig.7: Chromatogram of common anions in $50 \%$ combined industrial effluent

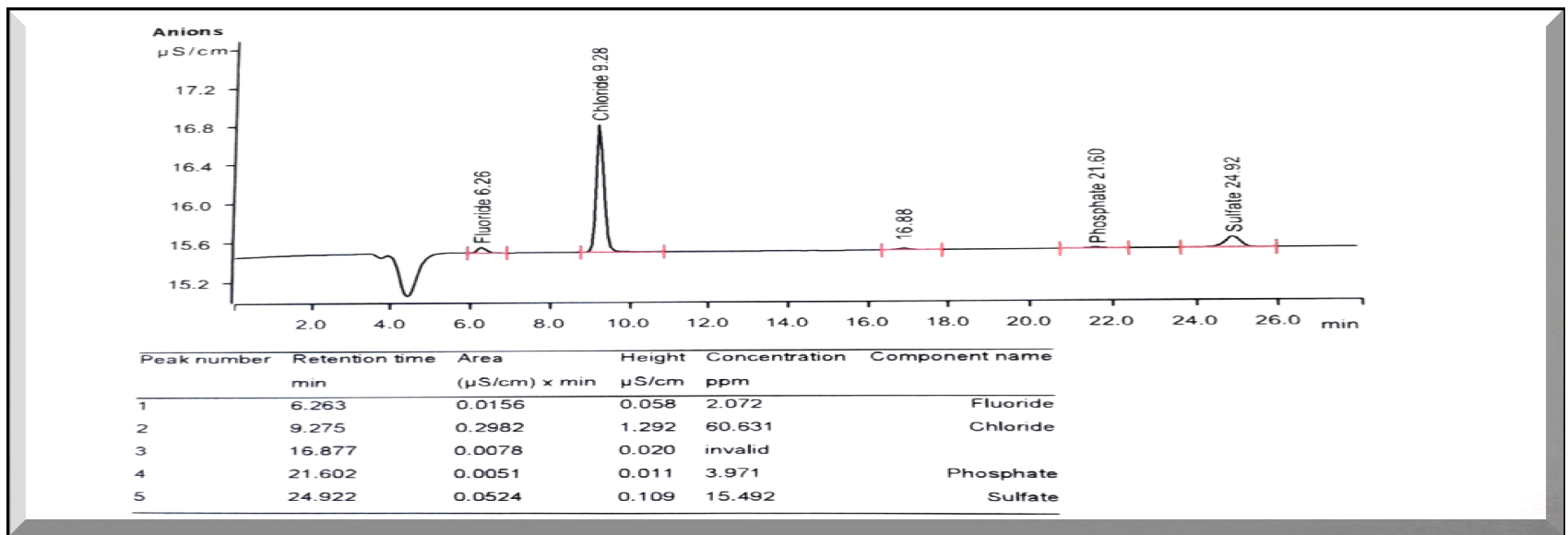

Fig.8: Chromatogram of common anions in $25 \%$ combined industrial effluent 
The analysis of cataionic data of combined industrial revealed that sodium, potassium and calcium in the $100 \%$ combined industrial effluent exhibited values of $0.212 \mathrm{ppm}, 0.024 \mathrm{ppm} 0.176 \mathrm{ppm}$ respectively Fig.1. and these values decreased with increase in dilution Figs. 2-4 whereas the analysis of anionic data of combined industrial revealed that anions fluoride, chloride, phosphate and sulphate in the $100 \%$ combined industrial effluent exhibited values of $11.545 \mathrm{ppm}, 1075.463 \mathrm{ppm}$, $57.587 \mathrm{ppm}$ and $126.875 \mathrm{ppm}$ respectively Fig.5 and these also values decreased with increase in dilution, Figs.6-8.The analysis of data of impact studies on seed germination of Phaseolus aureus revealed that control set and 25\% experimental set exhibited $100 \%$ value on $3^{\text {rd }}$ day after seed sowing .On $7^{\text {th }}$ day the seed germination index of control set and $25 \%$ experimental set exhibited value of 33.3 (Table 1 and 2). The seed germination index decreased with increase of combined industrial effluent i.e. $50 \%, 75 \%$ and $100 \%$ experimental sets exhibited values of seed germination index as $32.5,28.5$ and 27.8 respectively.The analysis of data of impact studies on seed germination of Phaseolus vulgaris revealed that control set exhibited $100 \%$ value on $7^{\text {th }}$ day with seed germination index of 21.8 after seed sowing. Whereas percentage seed germination and seed germination index in $25 \%, 50 \%, 75 \%$ and $100 \%$ experimental sets exhibited decreased value with increasing concentration of combined industrial effluent.The analysis of data of impact studies on seed germination of Viccia faba major revealed that control set exhibited $80 \%$ value on $7^{\text {th }}$ day with seed germination index of 21.6 after seed sowing. Whereas percentage seed germination $25 \%, 50 \%$, experimental sets exhibited increased value of $90 \%$ with increasing concentration of combined industrial effluent with seed germination index of 21.5 and 19.2 respectively after seed sowing. $75 \%$ and $100 \%$ experimental sets exhibited decreased values of percentage seed germination and seed germination index with increasing concentration of combined industrial effluent.The analysis of data of impact studies on seed germination of Vigna mungo seeds revealed that control set as well as $25 \%$, and $50 \%$,experimental sets exhibited $100 \%$ value on $3^{\text {rd }}$ day with seed germination index of 33.3 after seed sowing. Whereas percentage seed germination in $75 \%$ and
$100 \%$ experimental sets was also observed to be $100 \%$ but slightly delayed with seed germination index 30.6 and 28.3 respectively there by exhibiting slight inhibitory effect on seed germination of Vigna mungo seeds. he analysis of data of impact studies on seed germination of Vigna radiata seeds revealed that increasing concentration of combined industrial effluent exhibited stimulatory effect on percentage seed germination and seed germination index of Vigna radiata seeds. The analysis of data of impact studies on seed germination of Macrotyloma uniflorum seeds revealed that 25\%, experimental sets exhibited higher (90\%) value as compared that of control set and other experimental sets on $7^{\text {th }}$ day with seed germination index of 24.1 after seed sowing. Whereas percentage seed germination $100 \%$ experimental sets was observed to be $50 \%$ with seed germination index 11.6 thereby exhibiting inhibitory effect on seed germination of Macrotyloma uniflorum seeds. The analysis of data of impact studies on seed germination of Cicer arietum revealed that control set as well as $25 \%$, , $50 \%, 75 \%$ and $100 \%$ experimental sets exhibited $100 \%$ value. Whereas seed germination index exhibited decreased value in $25 \%,, 50 \%, 75 \%$ and $100 \%$ experimental sets thereby exhibiting slight inhibitory effect on seed germination of Black gram seeds. The analysis of data of impact studies on seed germination of Viccia faba minor seeds revealed that $25 \%$, experimental sets exhibited higher $(100 \%)$ value as compared that of control set and other experimental sets on $7^{\text {th }}$ day with seed germination index of 21.4 after seed sowing . The analysis of data of impact studies on seed germination of Pisum sativum revealed that control set exhibited $100 \%$ value on $7^{\text {th }}$ day with seed germination index of 23 after seed sowing. Whereas seed germination index in $25 \%, 50 \%, 75 \%$ and $100 \%$ experimental sets exhibited decreased values as compared that of control set with increasing concentration of combined industrial effluent. In general in most of studied seeds it was observed that the values of seed germination percentage and rate of seed germination index decreased with increasing effluent concentration. Sahai et al. (1985) while studying the impact of various concentrations of distillery effluent on the germination and growth behaviour of Phaseolus radiatus L. also observed that the values of seed germination percentage and rate of seed 
Ion chromatographic analysis of combined industrial

germination index decreased with increasing pigment content of Cajanus cajan L. observed that effluent concentration. Sahai and Srinivastava the effluent was highly acidic and predominantly (1986) while working on the effect of distillery rich in total dissolved solids, bicarbonates, waste on the seed germination, seedling growth and chlorides, calcium and nitrogen.

Table1. Seed germination index of leguminous seeds in different concentrations of combined industrial effluent

\begin{tabular}{|c|c|c|c|c|c|}
\hline \multirow[t]{2}{*}{ Type of seed } & \multicolumn{5}{|c|}{ Seed germination index in } \\
\hline & $\begin{array}{l}\text { Control } \\
\text { Set }\end{array}$ & $\begin{array}{l}\text { 25\% Exp. } \\
\text { Set }\end{array}$ & $\begin{array}{l}50 \% \\
\text { Exp. Set }\end{array}$ & $\begin{array}{l}75 \% \\
\text { Exp. Set }\end{array}$ & $\begin{array}{l}100 \% \\
\text { Exp. Set }\end{array}$ \\
\hline $\begin{array}{l}\text { Phaseolus aureus } \\
\text { (Rongi) }\end{array}$ & 33.3 & 33.3 & 32.5 & 28.5 & 27.8 \\
\hline Phaseolus vulgaris & 21.8 & 19.8 & 13.6 & 12 & 10.1 \\
\hline Viccia faba major & 21.6 & 21.5 & 19.2 & 15.8 & 9.7 \\
\hline Viccia faba minor & 20.6 & 21.4 & 22.3 & 24.8 & 26.5 \\
\hline Vigna mungo & 33.3 & 33.3 & 33.3 & 30.6 & 28.3 \\
\hline Vigna radiata & 23.3 & 24.1 & 29.8 & 29.8 & 30.2 \\
\hline $\begin{array}{l}\text { Macrotyloma } \\
\text { uniflorum }\end{array}$ & 16.1 & 24.1 & 14.7 & 11.4 & 11.6 \\
\hline Cicer arietum & 33.3 & 32.5 & 33.1 & 31.6 & 29.5 \\
\hline Pisum sativum & 23 & 20.6 & 18.7 & 16.6 & 9.2 \\
\hline
\end{tabular}

Table2:Percentage seed germination of leguminous seeds in different concentrations of combined industrial effluent

\begin{tabular}{|c|c|c|c|c|c|}
\hline \multirow[t]{2}{*}{ Type of seed } & \multicolumn{5}{|c|}{ Percentage Seed germination in } \\
\hline & Control Set & $\begin{array}{l}\text { 25\% Exp. } \\
\text { Set }\end{array}$ & $\begin{array}{l}50 \% \\
\text { Exp. Set }\end{array}$ & $\begin{array}{l}75 \% \\
\text { Exp. Set }\end{array}$ & $\begin{array}{l}100 \% \\
\text { Exp. Set }\end{array}$ \\
\hline Phaseolus aureus & $100 \%$ & $100 \%$ & $100 \%$ & $100 \%$ & $90 \%$ \\
\hline Phaseolus vulgaris & $100 \%$ & $90 \%$ & $80 \%$ & $70 \%$ & $60 \%$ \\
\hline Viccia faba major & $80 \%$ & $90 \%$ & $90 \%$ & $70 \%$ & $50 \%$ \\
\hline Viccia faba minor & $90 \%$ & $100 \%$ & $80 \%$ & $90 \%$ & $90 \%$ \\
\hline Vigna mungo & $100 \%$ & $100 \%$ & $100 \%$ & $100 \%$ & $100 \%$ \\
\hline Vigna radiata & $70 \%$ & $90 \%$ & $100 \%$ & $100 \%$ & $100 \%$ \\
\hline Macrotyloma uniflorum & $80 \%$ & $90 \%$ & $70 \%$ & $60 \%$ & $50 \%$ \\
\hline Cicer arietum & $100 \%$ & $100 \%$ & $100 \%$ & $100 \%$ & $100 \%$ \\
\hline Pisum sativum & $100 \%$ & $80 \%$ & $80 \%$ & $70 \%$ & $80 \%$ \\
\hline
\end{tabular}

The BOD values were quite high. They also observed increasing concentrations of the effluent induced a gradual decrease in the germination percentage and speed of germination index. The pure effluent was observed to be lethal. Dayama (1987) also made similar observation while working on influence of dyeing and textile water pollution on nodulation and germination of gram (Cicer arietinum L.) observed that the effluent was rich in chloride, bicarbonate and total dissolved solids. The BOD value was quite high.The

investigation showed that increasing concentration of effluent induced a general decrease in the germination percentage, seedling growth, nodule number and its fresh weight as well as the dry weight of the plant. Lower concentrations of effluent were not so toxic. Choudhary et al. (1987) while working on the effect of paper mill effluent on seed germination and seedling growth of maize observed that maize (Zea mays L.) seeds when kept for germination in petridishes containing equal amount of soil treated with different concentrations 
of effluent $(0.5,10,25,50,75,100 \%)$ yielded increased percent of germination and seedling growth upto $35 \%$ concentration, but it decreased at high concentration. At $25 \%$ concentration, overall growth of seedling was better than in control. In present study $25 \%$ combined industrial effluent exhibited enhanced value of seed germination of Macrotyloma uniflorum and Viccia faba minor seed as compared with that of control set as well as rest of experimental sets .Ray and Barman (1988) while studying the physiological responses of crop plants to effluents discharged from steel and tar, cycle and distillery industries on different varieties of rice, pulses and oil seeds observed retardation in growth of radicle with the increasing effluent concentration.Goel and Kulkarni (1994) carried their investigations on the effect of sugar factory waste on germination of gram seeds (Cicer arietinum L.) and came to the conclusion that the higher concentration of the waste suppressed the germination to a great extent. Sharma et al. (2002) assessed the toxicity of distillery effluent on seed germination, seedling growth and pigment content of sugar beet and observed progressive inhibition of seed germination and seedling growth at higher concentrations of the effluent.. They recommended that the effluent could be used for irrigation purpose after proper dilution. Doke et al (2011) assessed physico-chemical parameters of treated waste water effluents from a sugar industry and determined the effect of various concentrations $(0 \%, 20 \%, 40 \%, 60 \%, 80 \%$ and $100 \%)$ of effluent on seed germination, germination speed, peak value and the germination value of Vigna angularis, Chavali (Vigna cylindrical) and Jowar (Sorghum cernum) seeds. The low effluent $\mathrm{pH}$ (4.35), total dissolved solids, (TDS, $720 \mathrm{mg} / \mathrm{L}$ ) and chemical oxygen demand, (COD, $1330 \mathrm{mg} / \mathrm{L}$ ) indicated the high inorganic and organic content with an acidic load. Germination percentages and germination values decrease with increasing concentration of effluent.Overall from above studies it is concluded that combined industrial effluent in $100 \%$ concentration exhibited inhibitory effect on seed germination in all the studied seeds except Vigna radiata, Vigna mungo and Cicer arietum. In Macrotyloma uniflorum and Viccia faba major combined industrial effluent inhibited 50\% seed germination and in Phaseolus vulgaris it inhibited $40 \%$ of seed germination. This concludes that Macrotyloma uniflorum, Viccia faba major and Phaseolus vulgaris were more sensitive and Vigna radiata, Vigna mungo and Cicer arietum were found to resistant to combined industrial effluent.

\section{References}

Ameta, S. C., Punjabi, P. B., Kothari S. and Sancheti A. 2003. Effect of untreated and photcatalytically treated dying industry effluent on growth and biochemical parameters of Allium cepa (onion). Poll. Res. 22 (3), 389-392.

Choudhary, S.K., Jha, A.N. and Srivastava, D.K. 1987. Effect of paper mill effluent on seed germination and seedling growth of maize. Environ. Eco., 5 (2), 285-287.

Dayama, O.P. 1987. Influence of dyeing and textile water pollution on nodulation and germination of gram (Cicer arietinum L.). Acta Ecologica, 9 (1\&2), 34-37.

Doke K. M., Khan , E. M. , Rapolu , J.and Shaikh , A. 2011. Physico-chemical analysis of sugar industry effluent and its effect on seed germination of Vigna angularis, Vigna cylindrical \& Sorghum cerum. Annals of environmental Scienc, 5, 7-11

Goel, P.K. and Kulkarni, S.M. 1994. Effect of sugar factory waste on germination of gram seeds (Cicer arietinum L.). J. Environ. Polln., 1 (1), 35-43

Padhan, Abanti and Sahu, S, K. 1999. Effect of rice mill effluent on seed germination of some cereal crops. Poll Res. 18 (2), 187-189.

Ray, M. and. Barman, S.C 1988. Physiological responses of crop plant to waste effluents from (i) steel and tar (ii) cycle (iii) distillery industries application of the findings in measuring phytotoxicity. Indian Biologist, 20 (1), 1618.

Sahai, R., Shukla, N., Jabeen, S. and Saxena, P.K. 1985.. Pollution effect of distillery waste on the growth behaviour of Phaseolus radiatus L. Environmental Pollution series A, Ecological and biological 37 (3) 245 253.

Sahai, R. and Srinivastava, N. 1986. Effect of distillery waste on the seed germination, seedling growth and pigment content of Cajanus cajan L. J. Indian Botl. Soc., 65 (2), 208-211.

Sharma, V., Sharma, R. and Sharma, K.D. 2002. Distillery effluent effect on seed germination, early seedling growth and pigment content of sugarbect (Beta vulgaris). J. Environ. Biol. 23 (1), 77-80. 